\title{
Просветляющие покрытия на основе ZnO, полученные методом электронно-лучевого испарения
}

\author{
(С) Л.К. Марков, А.С. Павлюченко, И.П. Смирнова \\ Физико-технический институт им. А.Ф. Иофрфе Российской академии наук, \\ 194021 Санкт-Петербург, Россия \\ E-mail: I.markov@mail.ioffe.ru
}

Поступила в Редакцию 9 июля 2021 г.

В окончательной редакции 2 августа 2021 г.

Принята к публикации 2 августа 2021 г.

\begin{abstract}
Исследована возможность создания наноструктурированных просветляющих покрытий на основе $\mathrm{ZnO}$. Изучена зависимость структурных особенностей пленки от температуры нагрева подложки в процессе нанесения легированного алюминием материала оксида цинка. Показано, что изменением одного параметра, температуры подложки при нанесении материала, в диапазоне $20-600^{\circ} \mathrm{C}$ невозможно достичь требуемого структурирования пленки. С этой целью предложен подход, заключающийся в предварительном нанесении слоя Sn нанометровой толщины с последующим прогревом подложки до температуры нанесения основного слоя материала. Оптимизация режимов нанесения покрытия привела к получению среды, состоящей из большого количества нитевидных кристаллов с поперечными размерами в десятки нанометров и длиной в сотни нанометров, ориентированных преимущественно перпендикулярно подложке. Показано, что градиентный характер изменения плотности вещества, а следовательно, эффективного показателя преломления в направлении, перпендикулярном плоскости подложки, обеспечивает просветляющие свойства покрытия в широком диапазоне длин волн излучения и при распространении его в различных направлениях.
\end{abstract}

Ключевые слова: оксид цинка, прозрачные проводящие оксиды, просветляющие покрытия, электроннолучевое испарение, наноструктурированные пленки.

DOI: 10.21883/FTP.2021.12.51714.9712

\section{1. Введение}

Прозрачные проводящие оксиды (ТСО — transparent conductive oxides) получили широкое распространение в качестве контактов различных устройств. Довольно редкое сочетание прозрачности с электропроводностью позволяет подавать или снимать напряжение с оптически прозрачного элемента, что востребовано, например, в приборах оптоэлектроники и фотовольтаики (светоизлучающих диодах, лазерах, фотоприемниках), устройствах ввода и визуализации информации (дисплеях, сенсорных панелях), а также антистатических и антиобледенительных покрытиях. Наибольшую известность в классе ТСО получили 2 соединения: сложный оксид индия и олова (ITO), а также легированный (как правило, алюминием или оловом) оксид цинка. Так, например, в работе [1] рассмотрены свойства пленок оксида цинка, легированного алюминием (AZO), получаемых ВЧ магнетронным распылением при различных параметрах процесса нанесения материала.

Тонкие пленки ITO благодаря оптимальному соотношению прозрачности и электрической проводимости в настоящее время используются в подавляющем большинстве приборов, однако, ограниченные разведанные запасы индия в земной коре ставят вопрос о возможности его полного исчерпания в ближайшем будущем, что, соответственно, приводит к росту цены этого металла. Использование легированных пленок $\mathrm{ZnO}$ в качестве альтернативного варианта для создания прозрачных про- водящих покрытий помимо экономической составляющей также интересно в силу большей химической стойкости материала по сравнению с более подверженным деградации ITO [2].

В то же время материал ITO позволяет наносить пленки, в которых эффективный показатель преломления монотонно изменяется в направлении, перпендикулярном подложке. Такие так называемые градиентные покрытия за счет минимизации френелевского отражения на границах пленки обладают просветляющим эффектом в широком диапазоне длин волн и, соответственно, эффективно работают при распространении света в разных направлениях. Последнее обстоятельство выгодно отличает их от традиционных просветляющих покрытий, использующих конструктивную интерференцию для снижения отражения.

В основе способов получения градиентных пленок ITO лежит способность материала оксида индия и олова при определенных условиях нанесения формировать кристаллы вытянутой формы [3-8]. Возникающие нитевидные кристаллы с поперечными размерами $\sim 10-20$ нм в длину могут достигать нескольких микрон. Их рост осуществляется по механизму паржидкость-кристалл (ПЖК), или vapor-liquid-solid (VLS) в англоязычном варианте $[9,10]$ и может быть реализован методом электронно-лучевого испарения при нанесении на нагретую подложку [11]. Сама пленка имеет большое количество пустот за счет незаполненного материалом пространства между соседними кристаллами. 
При этом самоорганизация нитей в пленке, возникающая вследствие конкуренции между соседними нитями в процессе роста пленки, приводит к тому, что усредненная плотность материала в пленке убывает по мере удаления от подложки. Так как толщина нитей значительно меньше длины волны излучения, свет воспринимает такую среду как квазиоднородную, с монотонно меняющимся эффективным показателем преломления. Оптические проводящие покрытия на основе кристаллов ITO вытянутой формы могут быть использованы, например, для увеличения квантового выхода светоизлучающих диодов $[12,13]$. С другой стороны, получаемая пленка на ее внешних границах характеризуется экстремально низким значением эффективного показателя преломления материала, что также может быть использовано при создании приборов с уникальными свойствами. Так, например, размещая в верхних слоях пленки оптические элементы, можно достичь высоких значений контраста показателей преломления элемента и окружающей среды. В работе [14] было продемонстрировано, что перовскитный нанолазер, помещенный на поверхность структурированной пленки ITO, характеризуется значительно большей добротностью по сравнению с тем, что он показывает при его размещении на других подложках.

Однако, как обсуждалось выше, материал ITO обладает недостаточной химической стойкостью и может быть склонен к деградации при определенных условиях его эксплуатации. В случае структурированных пленок ситуация осложнена тем, что такие покрытия, состоящие из нанонитей, имеют большие удельные площади поверхности материала, что также может повысить их склонность к деградационным процессам. В работе [15] для защиты нанонитей ITO от действия окружающей среды каждая из них покрывалась изолирующим нанометровым слоем $\mathrm{Al}_{2} \mathrm{O}_{3}$, наносимым методом атомно-слоевого осаждения. Было показано, что при этом сохраняется градиентный характер эффективного показателя преломления пленки, и ее просветляющие свойства остаются неизменными. Однако создание такой пленки происходит в несколько этапов, что усложняет ее получение. Замена материала ITO на соединения на основе $\mathrm{ZnO}$ могло бы понизить себестоимость изготовления пленок, так как этот материал сам по себе имеет меньшую себестоимость и менее склонен к деградации.

Известно, что нанокристаллы $\mathrm{ZnO}$ вытянутой формы могут быть получены различными методами: распылительным пиролизом [16], синтезом из газовой фазы [17], гидротермальным [18]. Работа [19] посвящена обзору методов получения нанокристаллов на основе $\mathrm{ZnO}$. Гидротермальный метод является наиболее распространенным в настоящее время, однако поперечные размеры получаемых этим методом нанокристаллов составляют, как правило, сотни нанометров, что становится сравнимо с длиной волны излучения и значительно больше нанонитей ITO. Поэтому для увеличения вывода света могут быть задействованы дополнительные операции обработки покрытия. Так, например, в работе [20] методом травления нанокристаллов $\mathrm{ZnO}$ вытянутой формы были получены нанотрубки, которые в последствии закрывались тонким слоем $\mathrm{SiO}_{2}$ для увеличения просветляющего эффекта покрытия, а в работе [18] нанокристаллы $\mathrm{ZnO}$ покрывались сверху дополнительным наноструктурированным слоем $\mathrm{NiO}$, уменьшающим контраст показателя преломления на границе $\mathrm{ZnO}-$ окружающая среда.

Отметим, что методы выращивания кристаллов из растворов к тому же не всегда обеспечивают необходимую для полупроводниковой промышленности чистоту покрытия, что может повлиять на эксплуатационные характеристики приборов. Получение наноструктурированных пленок $\mathrm{ZnO}$ в рамках одного вакуумного процесса может обеспечить создание покрытий с улучшенными свойствами.

В настоящей работе исследовалась возможность нанесения наноструктурированных градиентных пленок на основе AZO в рамках одной процедуры вакуумного напыления.

\section{2. Результаты эксперимента и их обсуждение}

Эксперименты по получению наноструктурированных самоорганизующихся пленок AZO проводились на блоке электронно-лучевого напыления комбинированной установки производства фирмы Torr Int., США. В качестве материала для распыления использовались коммерчески доступные гранулы материала $\mathrm{ZnO}$, легированного 2\% Al, (AZO). Рабочая камера откачивалась до давления $10^{-7}$ мбар, в ней был предусмотрен нагрев подложкодержателя с образцами до температуры $600^{\circ} \mathrm{C}$. Контроль толщины пленок проводился в процессе их нанесения с помощью кварцевого датчика, измеряющего массу наносимого материала. Так как калибровка датчика осуществлялась на сплошном плотноупакованном материале, реальная толщина пленок, содержащих пустоты, отличалась от измеренной в процессе нанесения. Так как плотность пленки может быть различна для разных структурированных образцов, в дальнейшем при описании пленки мы будем исходить из массы напыленного материала. Для простоты изложения количество материала AZO, наносимое в одном процессе напыления пленки, мы будем характеризовать толщиной пленки без пустот, содержащей такое же количество материала. В этом случае будет говориться о количестве материала „в эквиваленте плотной пленки“. Таким образом, фраза: „была нанесена пленка толщиной $X$ нм в эквиваленте плотной пленки“ означает, что на подложку было осаждено такое же количество материала, как и при нанесении плотноупакованной пленки толщиной $X$ нм. Слой AZO осаждался в экспериментах со скоростью $\sim 15$ нм/мин, нагрев подложки варьировался во всем доступном диапазоне температур $20-600^{\circ} \mathrm{C}$.

Для изучения характеристик пленок исследуемые пленки осаждались на предметные стекла толщи- 

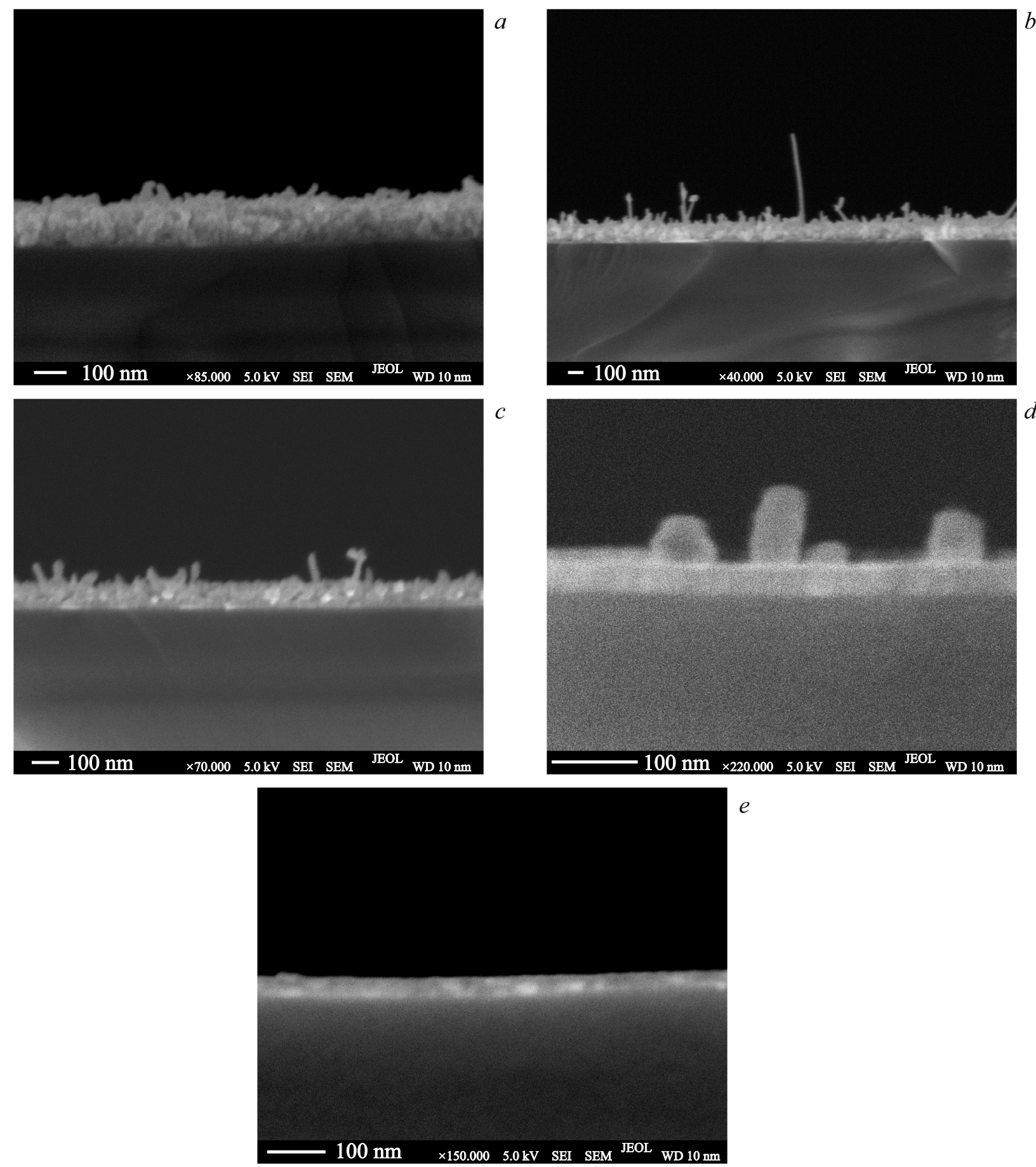

$e$

Рис. 1. РЭМ-изображения пленок, полученных при разных температурах подложек $T$, ${ }^{\circ} \mathrm{C}: a-20, b-175, c-250, d-330$, $e-600$.

ной 1.2 мм. Структура полученных таким образом образцов изучалась при помощи растровой электронной микроскопии. Исследовались также спектры пропускания и отражения образцов на спектрорадиометре Optronic Laboratories OL 770. Излучение падало на образец со стороны пленки, нормально к его поверхности.

Так как для получения структурированных пленок ITO электронно-лучевым испарением необходимо предвари- тельно разогреть подложку до высоких температур, при которых поддерживается рост кристаллов по механизму ПЖК, для пленок AZO также исследовалась зависимость структуры получаемой пленки от температуры нагрева подложки. На рис. 1 приведены РЭМ-изображения поперечных сколов образцов с пленками, полученными при разных температурах нанесения пленки. В экспериментах наносились пленки толщиной 160-180 нм 
в эквиваленте плотной пленки. Как видим из рис. 1, несмотря на то, что согласно диаграмме состояния системы $\mathrm{Zn}-\mathrm{Al}$ минимальная температура, при которой возможно существование жидкой фазы в этом бинарном соединении, находится на уровне $380^{\circ} \mathrm{C}$ (см., например, [21]), уже при температуре $175^{\circ} \mathrm{C}$ (рис. $\left.1, b\right)$ идет активное развитие нитевидных кристаллов с толщиной в несколько десятков нанометров, их длина при этом может достигать микронных значений. Такие параметры кристаллов близки к тому, что было получено ранее на материале ITO, однако их плотность недостаточна для создания покрытия с ощутимым градиентом плотности материала. При дальнейшем увеличении температуры подложки в процессе нанесения материала толщина кристаллов возрастает, длина уменьшается, но достичь требуемой плотности их на поверхности не удается (рис. $1, c, d)$. При приближении температуры подложки к $600^{\circ} \mathrm{C}$ рельеф полностью исчезает, а количество материала, осажденное на подложку, значительно меньше того, что измеряется датчиком (рис. 1,e). Наблюдаемое уменьшение толщины осажденного покрытия с увеличением температуры подложки, вероятно, связано с испарением материала.

Таким образом, эксперименты по варьированию температуры подложки при нанесении материала AZO показали, что достичь требуемого структурирования наносимой пленки изменением одного параметра, температуры нанесения материала, не представляется возможным. Для достижения поставленной задачи был предложен следующий подход: перед нанесением пленки AZO подложка предварительно покрывалась слоем Sn нанометровой толщины, а затем она нагревалась до требуемой температуры, впоследствии наносился слой материала AZO. Предварительное осаждение слоя Sn преследует две цели: во-первых, при прогреве предварительно нанесенного слоя олова он сворачивается в капли нанометрового размера, что инициирует рост кристаллов по механизму ПЖК; во-вторых, диаграмма состояния системы $\mathrm{Zn}-\mathrm{Sn}$ (см., например, [22]) предполагает возможность снижения температуры образования зародышевой капли в механизме ПЖК до $198.5^{\circ}$ С. При этом температура существования жидкой фазы в тройной системе $\mathrm{Zn}-\mathrm{Sn}-\mathrm{Al}$ (реализованной в нашем случае) при небольшом содержании $\mathrm{Al}$ незначительно отличается от этого значения [23]. Стоит отметить также, что оба элемента, как $\mathrm{Al}$, так и $\mathrm{Sn}$, активно используются в качестве легирующих добавок материала $\mathrm{ZnO}$ для увеличения его проводимости. Совместное легирование обоими материалами рассматривалось, например, в работах [24-26].

В экспериментах толщина наносимых нами пленок AZO составляла 300 нм в эквиваленте плотной пленки, а варьировалась как толщина предварительно наносимого слоя Sn в диапазоне от 0.5 до 7 нм, так и температура нагрева подложки при нанесении материала AZO в диапазоне от 175 до $500^{\circ} \mathrm{C}$. Эксперименты показали, что структура пленки зависит от изменения обоих указанных параметров. Так, например, из рис. 2, где приведены РЭМ-изображения пленок, полученных в процессе оптимизации процесса получения покрытия, видно, что при одном значении температуры нанесения пленки $\left(330^{\circ} \mathrm{C}\right)$ степень развитости поверхности определяется толщиной подслоя $\mathrm{Sn}$, который составляет для образцов, приведенных на рис. 2, $a$ и $b, 0.5$ и 7 нм соответственно. Несмотря на то что при увеличении толщины подслоя олова при данной температуре стимулируется рост нитевидных кристаллов, их плотность по-прежнему недостаточна для формирования среды с искомым значением градиента плотности. Влияние температуры на степень структурирования пленки продемонстрировано на рис. 2, $c$ и $d$, где приведены изображения пленок $\mathrm{AZO}$, нанесенных на подслой олова одинаковой толщины (1 нм), но при температурах 450 и $500^{\circ} \mathrm{C}$ соответственно. Как видим, при увеличении температуры с 450 до $500^{\circ} \mathrm{C}$ начинается активный рост большого количества кристаллов вытянутой формы, и их плотность на единицу поверхности заметно увеличивается, однако толщина кристаллов достигает значения $60 \mathrm{Hм}$ при данных параметрах нанесения покрытия, что в разы превышает толщину кристаллов в структурированных пленках ITO. Однако, так как размеры кристаллов все еще значительно меньше длины волны видимого света, как будет показано далее, пленка обладает заметным просветляющим эффектом. В процессе проведения экспериментов оказалось, что в предлагаемом способе нанесения покрытия с предварительным напылением слоя олова нагрев подложки до температуры $500^{\circ} \mathrm{C}$ способствует активному зарождению и вытягиванию кристаллов при различных толщинах подслоя $\mathrm{Sn}$.

Оптимальные с точки зрения структурирования пленок результаты были получены при увеличении толщины предварительно наносимого подслоя олова. На рис. 3 приведены изображения пленок, осаждавшихся при температуре подложкодержателя $500^{\circ} \mathrm{C}$, с толщиной подслоя Sn 2 и 4 нм. Обе пленки похожи по структуре и аналогично структурированным пленкам ITO состоят из „леса“ нитевидных кристаллов, начинающих свой рост из более плотного, зародышевого слоя, обеспечивающего проводимость покрытия. Так как длина кристаллов различна, создается заметный градиент плотности материала в направлении, перпендикулярном плоскости подложки точно так же, как это наблюдается в структурированных пленках ITO. Кроме того, толщина самих кристаллов в данных пленках заметно уменьшается при удалении от подложки, что должно создавать дополнительный вклад в градиент плотности материала, а следовательно, и в градиент его эффективного показателя преломления.

Несмотря на близость структуры изображенных на рис. 3 пленок, их оптические характеристики различны. На рис. 4 приведены спектры пропускания и отражения образцов с пленками, полученными при температуре подложкодержателя $500^{\circ} \mathrm{C}$. Как видим, несмот- 

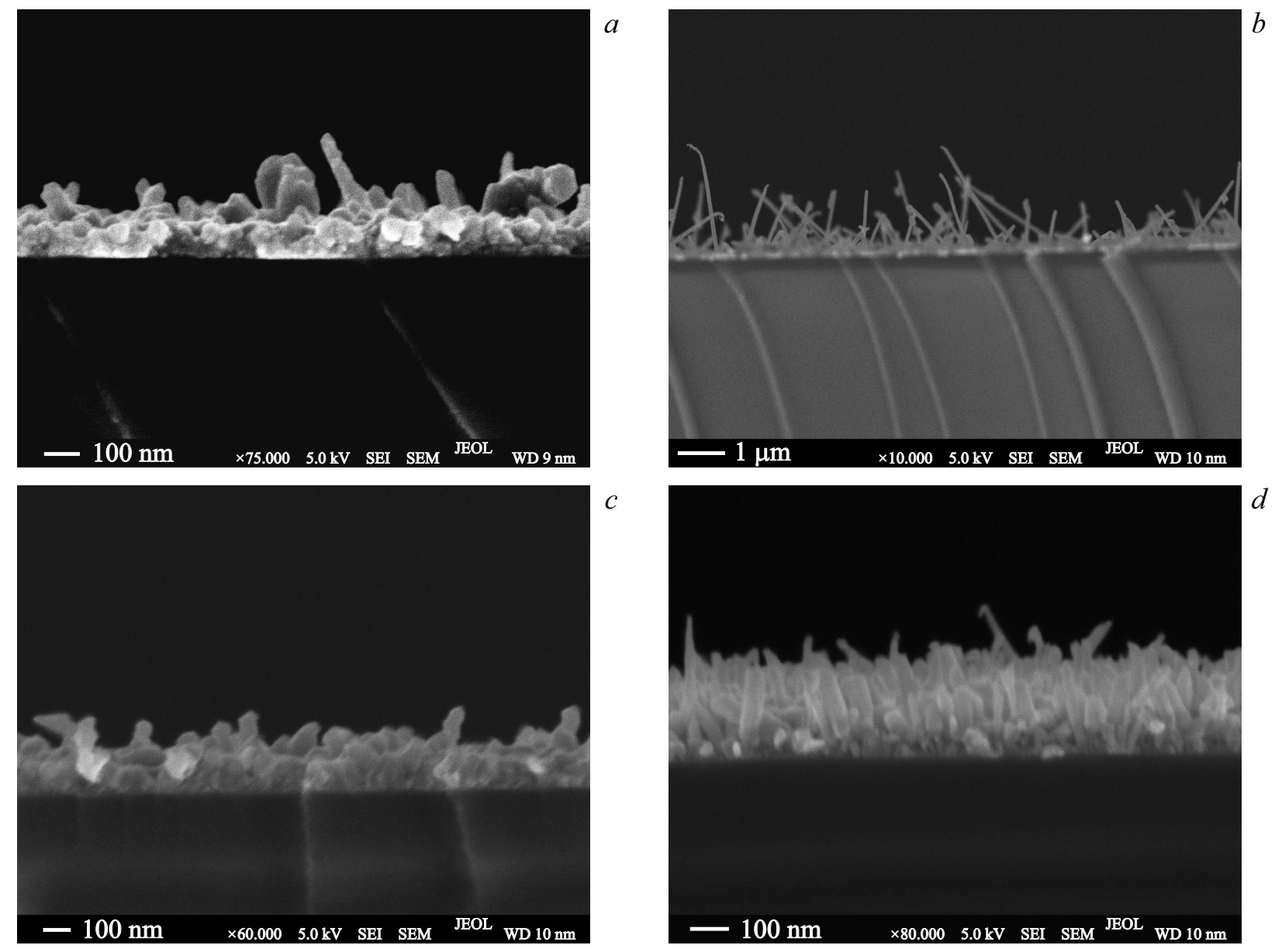

Рис. 2. РЭМ-изображения пленок с подслоем $\mathrm{Sn}$ различной толщины $(d)$, полученных при разных температурах подложек $(T)$ : $a-d=0.5 \mathrm{HM}, T=330^{\circ} \mathrm{C} ; b-d=7 \mathrm{HM}, T=330^{\circ} \mathrm{C} ; c-d=1 \mathrm{HM}, T=450^{\circ} \mathrm{C} ; d-d=1 \mathrm{HM}, T=500^{\circ} \mathrm{C}$.
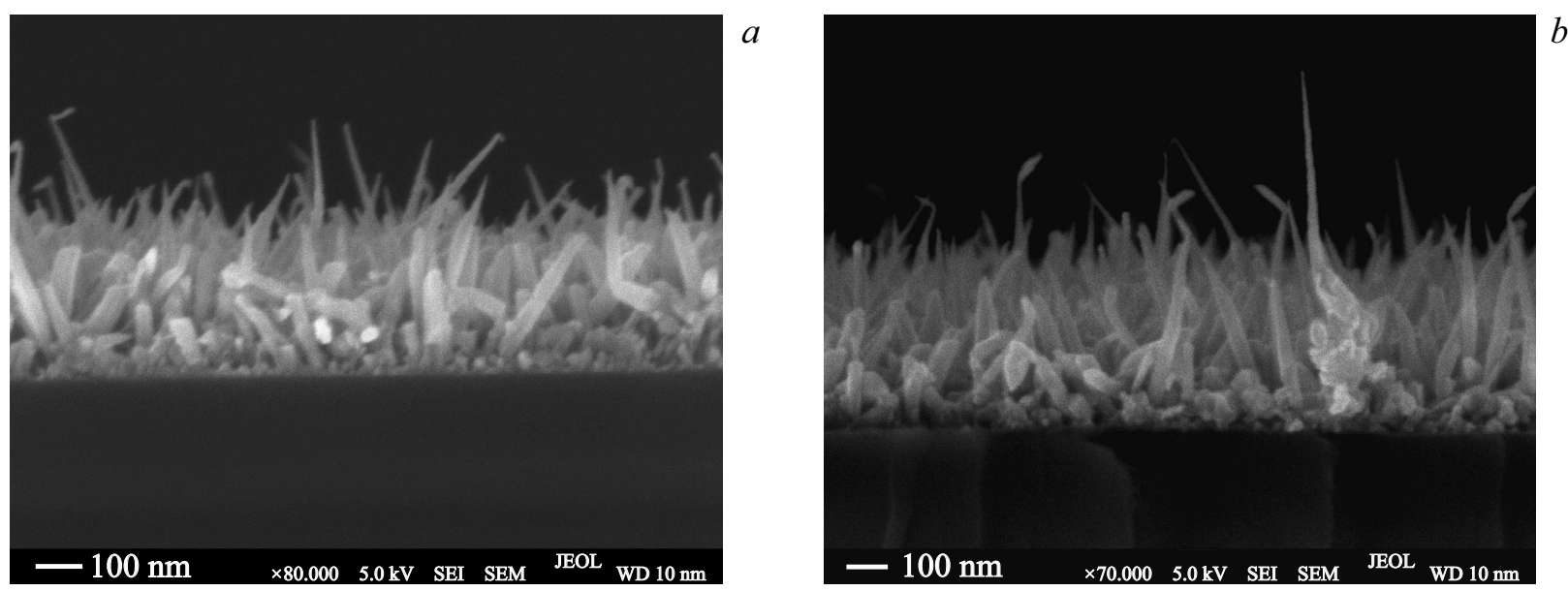

Рис. 3. РЭМ-изображения пленок с подслоем Sn толщиной $2(a)$ и 4 нм $(b)$, полученных при температуре подложки $500^{\circ} \mathrm{C}$.

pя на то что содержание олова в пленках с подслоем толщиной 1,2 и 4 нм незначительно и составляет 0.33 , 0.66 и 1.33 об\% соответственно, наблюдается заметный прирост поглощения света в пленке при увеличении содержания Sn. При этом на кривых зависимости ко- эффициента пропускания образцов с пленками от длины волны отсутствуют выраженные интерференционные экстремумы, характерные для плотных пленок даже с меньшим, чем у исследованных нами, массовым содержанием материала [24]. Амплитуды отражения всех при- 


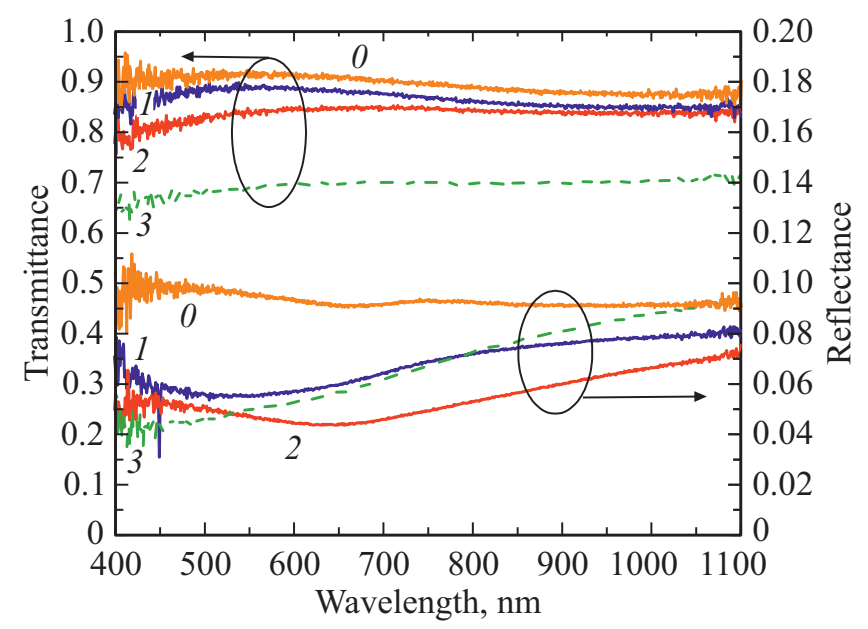

Pис. 4. Спектры пропускания и отражения образцов с пленками AZO, осажденными при температуре подложки $500^{\circ} \mathrm{C}$, с подслоем $\mathrm{Sn}$ толщиной 1 (1), 2 (2) и 4 нм (3), а также стеклянной подложки без покрытия $(0)$.

веденных на рис. 4 образцов с пленками во всем диапазоне длин волн ниже амплитуды отражения от исходной стеклянной подложки, использовавшейся для нанесения покрытия (кривая 0 на рис. 4). Таким образом, можно утверждать, что при нанесении пленок на стеклянную подложку наблюдаемый на РЭМ-изображениях градиентный характер плотности вещества в пленке приводит к подавлению отражения на границе стекло-воздух в широком диапазоне длин волн.

\section{3. Заключение}

Таким образом, в настоящей работе методом электронно-лучевого испарения были получены наноструктурированные пленки на основе AZO, обладающие градиентным характером изменения плотности вещества и, следовательно, эффективного показателя преломления в направлении, перпендикулярном плоскости подложки. Такие пленки за счет минимизации френелевского отражения на границе раздела двух сред с различными значениями показателя преломления могут быть использованы как эффективные просветляющие покрытия в широком диапазоне длин волн излучения и при распространении его в различных направлениях. Предложенный подход, заключающийся в формировании зародышевого слоя из расплавленных капель $\mathrm{Sn}$, совместно с оптимизацией режимов нанесения материала $\mathrm{AZO}$ позволил добиться одновременного роста большого количества нитевидных кристаллов с нанометровыми поперечными размерами и длиной в сотни нанометров. Как показали эксперименты, структура получаемого покрытия, а также его оптические свойства определяются как толщиной предварительно наносимого слоя $\mathrm{Sn}$, так и температурой подложки в процессе нанесения материала AZO. Прозрачные проводящие покрытия, сформированные пред- ложенным способом, кроме просветляющей способности также обладают экстремально низким значением показателя преломления на внешней границе покрытия за счет малой плотности вещества в ней.

\section{Конфликт интересов}

Авторы статьи заявляют об отсутствии конфликта интересов.

\section{Список литературы}

[1] R.N. Chauhan, R.S. Anand, J. Kumar. Phys. Status Solidi, 211, 2514 (2014).

[2] W.S. Leung, Y.C. Chan, S.M. Lui. Microelectron. Eng., 101, 1 (2013).

[3] X.Y. Xue, Y.J. Chen, Y.G. Liu, S.L. Shi, Y.G. Wang, T.H. Wang. Appl. Phys. Lett., 88, 201907 (2006).

[4] A.J. Chiquito, A.J.C. Lanfredi, E.R. Leite. J. Phys. D: Appl. Phys., 41, 4 (2008).

[5] H.K. Yu, W.J. Dong, G.H. Jung, J.L. Lee. ACS Nano, 5, 8026 (2011).

[6] R. Rakesh Kumar, V. Gaddam, K. Narasimha Rao, K. Rajanna. Mater. Res. Express, 1, 35008 (2014).

[7] G.O. Setti, D.P. De Jesus, E. Joanni. Mater. Res. Express, 3, 105021 (2016).

[8] A.L. Beaudry, R.T. Tucker, J.M. Laforge, M.T. Taschuk, M.J. Brett. Nanotechnology, 23, 105608 (2012).

[9] G. Meng, T. Yanagida, K. Nagashima, H. Yoshida, M. Kanai, A. Klamchuen, F. Zhuge, Y. He, S. Rahong, X. Fang, S. Takeda, T. Kawai. J. Am. Chem. Soc., 135, 7033 (2013).

[10] H.K. Yu, J.L. Lee. Sci. Rep., 4, 1 (2014).

[11] Л.К. Марков, А.С. Павлюченко, И.П. Смирнова, С.И. Павлов. ФТП, 52, 1228 (2018).

[12] M.J. Park, C.U. Kim, S.B. Kang, S.H. Won, J.S. Kwak, C.M. Kim, K.J. Choi. Adv. Opt. Mater., 5, 1600684 (2017).

[13] Z. Gong, Q. Li, Y. Li, H. Xiong, H. Liu, S. Wang, Y. Zhang, M. Guo, F. Yun. Appl. Phys. Express, 9, 082102 (2016).

[14] D.I. Markina, A.P. Pushkarev, I.I. Shishkin, F.E. Komissarenko, A.S. Berestennikov, A.S. Pavluchenko, I.P. Smirnova, L.K. Markov, M. Vengris, A.A. Zakhidov, S.V. Makarov. Nanophotonics, 9, 3977 (2020).

[15] Л.К. Марков, А.С. Павлюченко, И.П. Смирнова, М.В. Меш, Д.С. Колоколов. ФТП, 55, 365 (2020).

[16] E. Bacaksiz, S. Aksu, S. Yilmaz, M. Parlak, M. Altunbaş. Thin Sol. Films, 518, 4076 (2010).

[17] P. Yang, H. Yan, S. Mao, R. Russo, J. Johnson, R. Saykally, N. Morris, J. Pham, R. He, H.J. Choi. Adv. Funct. Mater., 12, 323 (2002).

[18] W.-S. Lee, S.-H. Kwon, H.-J. Choi, K.-G. Im, H. Lee, S. Oh, K.-K. Kim. Micromachines, 11, 346 (2020).

[19] Y. Zhang, M.K. Ram, E.K. Stefanakos, D.Y. Goswami. J. Nanomater., 2012, 22 (2012).

[20] S. Oh, K. Ha, S.H. Kang, G.J. Yohn, H.J. Lee, S.J. Park, K.K. Kim. Nanotechnology, 29, 15301 (2018).

[21] J.L. Murray. Bull. Alloy Phase Diagrams, 4, 55 (1983).

[22] J.-H. Bae, K. Shin, J.-H. Lee, M.-Y. Kim, C.-W. Yang. Appl. Microsc., 45, 89 (2015).

[23] J. Drápala, G. Kostiuková, M. Losertová. IOP Conf. Ser.: Materials Science and Engineering (Institute of Physics Publishing, November 23, 2017) v. 266, p. 012002. 
[24] A. Mallick, D. Basak. Appl. Surf. Sci., 410, 540 (2017).

[25] Z. Jin, L. Qiao, C. Guo, Z. He, L. Liu, M. Rong. Optik (Stuttg.), 127, 1988 (2016).

[26] X. Tian, Z. Pan, H. Zhang, H. Fan, X. Zeng, C. Xiao, G. Hu, Z. Wei. Ceram. Int., 39, 6497 (2013).

Редактор А.Н. Смирнов

\section{ZnO-based Antireflection Layers Obtained by the Electron Beam Evaporation}

\section{L.K. Markov, A.S. Pavluchenko, I.P. Smirnova}

loffe Institute,

194021 St. Petersburg, Russia

Abstract The possibility of creating nanostructured antireflection coatings based on $\mathrm{ZnO}$ has been investigated. The dependence of structural features of the film on the substrate heating temperature during deposition of an aluminum-doped zinc oxide (AZO) has been studied. It is shown that it is impossible to obtain the required structural properties of the film by changing one parameter, the substrate temperature during deposition of the material, in the range of $20-600^{\circ} \mathrm{C}$. For this purpose, an approach has been suggested, which consists in preliminary deposition of a nanometer-thick Sn layer with subsequent substrate heating up to the temperature of deposition of the main material layer. The optimization of coating deposition conditions led to the fabrication of a medium consisting of many whiskers with transverse dimensions of tens of nanometers and a length of hundreds of nanometers, which are oriented mainly perpendicular to the substrate. It is shown that the gradient nature of a change in the material density, and, hence, in the effective refractive index in the direction perpendicular to the substrate plane, provides antireflection properties of the coating over a wide range of wavelengths as well as in different directions of light propagation. 